\title{
Aids e covid-19: Entre Olhares e Experiências
}

Aids and covid-19: Between Looks and Experiences

Aids y covid-19: Entre Miradas y Experiencias

\author{
Breno de Oliveira Ferreira ${ }^{1}$ \\ Universidade Federal do Amazonas (UFAM)
}

\author{
André Luiz Machado das Neves
}

Universidade do Estado do Amazonas (UEA)

\begin{abstract}
Resumo
A pandemia do novo coronavírus trouxe inúmeras mudanças sociais, culturais, econômicas e de saúde, e, com isso, vários especialistas têm lançado mão de diferentes abordagens para melhor compreender o fenômeno. Neste ensaio, o objetivo foi analisar elementos importantes na conformação da epidemia de aids que podem nos indicar caminhos e pistas para a compreensão de alguns aspectos da pandemia do novo coronavírus. Não se trata de um estudo comparativo, mas sim de uma análise crítico-reflexiva de espelhamentos possíveis, nos seguintes pontos: o estigma e a discriminação, o dialeto de guerra, vulnerabilidades, prevenção, políticas e tratamento. Para que possamos aprender com as experiências do campo da aids, precisamos compreender os elementos sociais e culturais que influenciam no processo saúde-adoecimento-cuidado da covid-19, os quais, em meio à necessidade de dar respostas tão imediatas, podem restringir o campo de visão e as dimensões que envolvem todo um complexo.
\end{abstract}

Palavras-chave: covid-19, aids, epidemias

\begin{abstract}
The pandemic of the new coronavirus brought numerous social, cultural, economic, and health changes; and, with this, several specialists have resorted to different approaches to better understanding the phenomenon. In this essay, the objective was to analyze important elements in the conformation of the aids epidemic that can indicate paths and clues for understanding some aspects of the pandemic of the new coronavirus. This is not a comparison, but a critical-reflective analysis on the following points: stigma and discrimination, the war dialect, vulnerabilities, prevention, policies, and treatment. To learn, therefore, from experiences in the field of aids, we need to understand the social and cultural elements that influence the covid-19 health-illness-care process, which, amid the need to provide such immediate responses, may restrict the field of vision and dimensions that involve an entire complex.
\end{abstract}

Keywords: covid-19, aids, epidemics

\section{Resumen}

La pandemia del nuevo coronavirus trajo numerosos cambios sociales, culturales, económicos y de salud, y, con eso, varios especialistas han recurrido a diferentes enfoques para comprender mejor el fenómeno. Una de ellas es observar las respuestas de las epidemias de sida y establecer aproximaciones que pueden ser importantes para el contexto actual de la pandemia de covid-19. En este ensayo, el objetivo fue analizar elementos importantes en la conformación de la epidemia de sida que pueden indicar caminos y pistas para comprender algunos aspectos de la pandemia del nuevo coronavirus. Esto no es una comparación, sino un análisis crítico-reflexivo sobre los siguientes puntos: estigma y discriminación, dialecto de guerra, vulnerabilidades, prevención, políticas y tratamiento. Para que podamos aprender de las experiencias en el campo del sida, debemos comprender los elementos sociales y culturales que influyen en el proceso de atención de salud-enfermedad de covid-19, los cuales, en medio de la necesidad de proporcionar tales respuestas inmediatas, pueden restringir el campo de visión y dimensiones que involucran todo un complejo.

Palabras clave: covid-19, sida, epidemias

\footnotetext{
${ }^{1}$ Endereço para contato: Universidade Federal do Amazonas, Faculdade de Psicologia, Av. General Rodrigo Octavio Jordão Ramos, 1200, Coroado I, Manaus, AM, CEP 69067-005. Telefone: (86) 99959-3991. E-mail: breno.oli@hotmail.com
} 


\section{Introdução}

A covid-19, doença causada pelo coronavírus denominado SARS-CoV-2, foi identificada pela primeira vez em dezembro de 2019, em Wuhan, na China (Zhu et al., 2020). Em 30 de janeiro de 2020, a Organização Mundial da Saúde (OMS) declarou que a epidemia constituía uma Emergência de Saúde Pública de Importância Internacional (ESPII) e, em 11 de março, uma pandemia. Foi assim que a OMS sugeriu que todos os países adotassem o protocolo do isolamento físico como a principal estratégia a ser tomada para minimizar a transmissão comunitária (World Health Organization, 2020).

Esse cenário anunciava a chegada de um vírus que se alastrava no mundo e deixava rastros imensuráveis na saúde, economia, segurança, educação e em vários outros dispositivos sociais (The Lancet, 2020). No Brasil não foi diferente, um complexo de tensões e disputas de narrativas se instaurou em um país que já vinha enfrentando inúmeros problemas de desigualdades e polarização social (Barreto et al., 2020).

Nessa direção, foi comum observarmos vários empreendimentos de instituições e atores sociais problematizando questões advindas com a pandemia da covid-19, entre elas, utilizando a aids como um exemplo de epidemia já vivenciada globalmente (Pozniak et al., 2020; Hargreaves \& Davey, 2020). Outros pesquisadores brasileiros também vêm fazendo um processo semelhante de análise entre a covid-19 e outras epidemias estudadas previamente, como a de zika (Segata, 2020) e de ebola (Pimenta, 2020). As demandas, preocupações e necessidades já conhecidas de outras realidades poderão, a partir desses espelhamentos, encaminhar sugestões e informações a autoridades sanitárias, tecnológicas e assistenciais.

Diante desse cenário, surgiu-nos a seguinte questão: a epidemia de aids nos fornece lições para compreender as respostas à pandemia do novo coronavírus? Apresentamos este ensaio com o objetivo de trazer uma contribuição teórico-reflexiva desenvolvida por meio desse questionamento, buscando ir além da discussão do âmbito biomédico. Procuramos conciliar seis temas que podem ser teoricamente diferenciados, contudo, inter-relacionados às respostas da pandemia do novo coronavírus e seus entre olhares e experiências com a aids.

\section{Notas Preliminares entre a Pandemia da Covid-19 e a Aids}

Todo esse enredo parece ter sido remontado há mais de três décadas, quando os primeiros casos de pessoas infectadas pelo vírus da aids, o HIV, foram detectados na África e nos Estados Unidos, em meados de 1980 (Bastos, 2006). No Brasil, um conjunto de tentativas, ações e assimetrias regionais e populacionais marcaram toda uma trama das fases dessa epidemia. A aids, diferentemente da covid-19, tem um longo percurso sociopolítico na nossa história. A sua última epidemia, e a mais marcante, trouxe um conjunto de reações da cultura, da economia, da política e da sociedade em si na formatação de uma nova proposta de compreensão do processo saúde-adoecimento-cuidado, o que é essencial para o campo das políticas públicas. Não é à toa que vários pesquisadores e pesquisadoras do campo da aids têm sido convocados para atuarem nas pesquisas recentes da covid-19.

Já é notório que a infecção causada pelo SARS-CoV-2 é diferente daquela causada pelo HIV. A infecção pelo HIV, por exemplo, quando não tratada, geralmente leva ao óbito, já a SARS-CoV-2 mata um número bem menor de pessoas que não são tratadas. As mudanças de comportamento que podem diminuir a transmissão também são diferentes: comportamento 
sexual, principalmente, para a aids; e proximidade física e lavagem das mãos, para a covid-19. Os primeiros casos de pessoas infectadas pelo HIV dobraram em um período de seis a doze meses, já para a covid-19 o intervalo serial é uma questão de dias (Hargreaves \& Davey, 2020). Segundo a Unaids (2019), 74,9 milhões de pessoas foram infectadas pelo HIV desde o início da epidemia (até o fim de 2018). Hoje, 5,5 milhões de pessoas já foram (ou estão) infectadas pelo novo coronavírus (Brasil, 2020). Enquanto a covid-19 tem uma resposta preocupante em países em desenvolvimento, até pelas fragilidades dos sistemas de saúde, a prevenção da aids é uma questão mundial. Contudo, um conjunto de experiências e lições podem ser extraídas de seus contextos, ponderadas e explanadas.

Por isso, propusemo-nos a analisar questões importantes na conformação da epidemia de aids que podem nos indicar caminhos e pistas para a compreensão de alguns aspectos da pandemia do novo coronavírus. Vale destacar que não se trata de um comparativo de equivalências metamerizadas, mas de um conjunto de diálogos possíveis entre as duas arenas - aids e covid-19.

A covid-19 e a aids - como em um tecido - formam o anverso e o reverso das relações sociais. A menção aqui ao tecido não é meramente casual, uma vez que as relações sociais parecem ser frequentemente pensadas como uma peça a ser usada por um grupo, e, portanto, a forma como esta é tecida despertará interesse ou não de envolver, tocar etc. Uma peça é reversível quando a operação de dobra permite a transição entre ambos os lados do tecido (relações). A intercalação entre o anverso e o reverso é a diferença entre um estado descontínuo e um estado contínuo: se, no primeiro, por exemplo, o trançado das figuras e cores é nítido, no segundo, os motivos se desvanecem até perderem seus contornos e cores. Ou seja, o que pretendemos refletir não são os domínios da existência como se fossem a mesma coisa, mas o modo em que covid-19 e aids entram em relação, bem como o modo em que se reticulam e transitam entre si por meio de uma linha que as distingue e as relaciona ao mesmo tempo.

À frente desta seção introdutória, apresentamos seis subseções-temas que delineiam as reflexões sobre as experiências de covid-19 e aids. Na primeira, a reflexão aciona as noções de estigma e discriminação, no campo das ciências humanas e sociais, na busca pelos fundamentos das representações das pessoas no cotidiano da pandemia do novo coronavírus e da aids. Na segunda subseção, nominada de "dialetos de guerra", consideramos que é o ponto nodal para fazermos o andamento das similaridades do fenômeno em tela. Na terceira vulnerabilidades - refletimos sobre como essa noção atravessou as estratégias das agendas diante da pandemia da covid-19 e da aids. Dando seguimento ao trajeto teórico-reflexivo a que se propõe este texto, lançamos mão das estratégias de prevenção utilizadas nos contextos em discussão. E, nas duas últimas subseções de temas reflexivos, trazemos a perspectiva de políticas e tratamento e seus entre olhares. Na última, fazemos apontamentos para fechar o raciocínio deste ensaio, com lições para serem pensadas agora e aprofundadas ulteriormente.

\section{O Estigma e a Discriminação}

E por falar em estigma, preconceito e discriminação, conceitos que têm sido cunhados a partir de diferentes olhares e em diferentes pesquisas, alguns pontos precisam ser mais 
bem esclarecidos e considerados. O debate sobre a natureza do estigma esteve atrelado, principalmente, ao trabalho clássico de Erving Goffman (1980), que estudou vários públicos - pessoas com deficiência física, pessoas em sofrimento psíquico e homossexuais - que tinham "marcas" de uma identidade "deteriorada", fato que levaria a condenações morais e exclusão na/da sociedade. Já a ideia de preconceito esteve posta inicialmente no campo da Psicologia Social, trazida por Gordon Allport (1954), que, em seu trabalho seminal, define como uma espécie de "antipatia" - que pode ser sentida por um grupo ou um indivíduo. Em anos recentes, a discussão tanto de estigma como de preconceito tem contribuído para entender as discriminações contra alguns sujeitos e seus coletivos. Para Parker e Aggleton (2003), a discriminação se configura por meio de atitudes e ações de valência negativa e pejorativa adotadas por alguns, em relação a questões e valores específicos de um grupo minoritário ou identitário, ou seja, a discriminação é a forma mais efetivada do estigma e do preconceito. O estigma e o preconceito estão mais presentes no campo teórico, e a discriminação no campo prático e cotidiano das relações.

Com o início da epidemia de aids em 1980, uma fábula de Hs foi tensionada. Bastos (2006) se utiliza da ideia de caça às bruxas para discorrer sobre esse período. Para o autor, havia uma classificação de pessoas e a personificação de histórias para mostrar que existiam preferências, hoje equivocadas, por homossexuais (H1), haitianos (H2), hemofílicos (H3) e heroinômanos $(\mathrm{H} 4)$ na epidemiologia de uma doença que se instalava. Esses grupos de Hs foram postos como verdadeiros "vetores" do HIV. O que a ciência da época legitimou tem levado anos para a mesma ciência desconstruir. Hoje, o Ministério da Saúde se utiliza da perspectiva de populações-chave, em vez de grupos de risco, para indicar que gays e outros homens que fazem sexo com homens, pessoas trans, pessoas que usam álcool e outras drogas, pessoas privadas de liberdade e trabalhadores sexuais vivem vulnerabilidades constantes ao HIV.

Terto Júnior (2002), por exemplo, reforça que a associação chegou a tal ponto que a aids começou a ser chamada de GRID (Gay-Related Immunodeficiency) nos espaços mais científicos e de "câncer gay", "peste gay" ou "peste rosa" pelas mídias e dispositivos de opinião pública. Vários estudos (Ferreira \& Bonan, 2020; Terto Jr., 2015) já mostraram como o estigma da aids ainda se faz tão presente nos serviços de saúde e, especialmente, no trabalho de profissionais de saúde, que de antemão deveriam ofertar cuidado livre de qualquer julgamento. Podemos dizer também que a violência simbólica reforça as estruturas de dominação historicamente construídas pelos padrões de moralidades (igreja, família, escola e Estado) e fortalece a assimetria de relações, que, de forma "suave, insensível, invisível para suas próprias vítimas, se exerce essencialmente pelas vias puramente simbólicas do conhecimento, ou mais precisamente, do desconhecimento, do reconhecimento, ou, em última instância, do sentimento" (Bourdieu, 2003, p. 7).

No atual cenário, mesmo sabendo a necessidade de desnaturalizar a ideia de grupo de risco - hegemonicamente construída pelos grupos de dominação -, voltamos a apresentar grupos específicos no contexto da pandemia de covid-19: pessoas com comorbidades e idosos (Brasil, 2020). Sabe-se que o SARS-CoV-2 circula por toda a população, e o risco de adoecer é maior em alguns grupos - diferentemente daqueles em maior risco para o HIV. No entanto, parece-nos que houve uma reinvenção da ideia de risco associada ao contágio. Por vezes, a doença chega antes mesmo da resposta do corpo biológico de cada sujeito. Não é incomum que pessoas que testaram positivo para a covid-19 sejam estigmatizadas e sofram 
discriminações diversas, ou que profissionais que trabalham em serviços essenciais sejam excluídos de atividades comuns da vida. Inclusive, vários casos foram veiculados pelos meios de comunicação relatando hostilidade e até mesmo agressão física contra profissionais da saúde no Brasil.

No caso da covid-19, as autoridades de saúde pública também têm construído um discurso de proteção de alguns grupos pelo temor de maior gravidade da doença, enquanto os "grupos de risco" do contexto da aids foram marginalizados, especialmente no início da pandemia. Muitas pessoas (governadores, personalidades públicas, pessoas comuns) que testaram positivamente para covid-19 foram para as redes sociais divulgar o status sorológico positivo, enquanto são raras as manifestações públicas de pessoas vivendo com HIV, principalmente por conta do medo do estigma e da discriminação. Não obstante, é importante perceber o quanto a soropositividade se inscreveu na ordem da moralidade, da normalidade e da "abjeção" em ambas as arenas.

De forma geral, podemos dizer que as formas de controle de corpos e a negação de novas insurgências voltam aos padrões de uma cultura que se faz e refaz higienista e eurocêntrica. Continuamos a classificar quem são os aptos e os não aptos a voltar ao trabalho, quem foram as pessoas testadas e as não testadas, quem pode ir ao supermercado e quem não pode e, assim, as randomizações, enumerações e estatísticas passaram a traçar novos padrões de normalidade no centro desse debate.

Castiel, Guilam e Ferreira (2010) dizem que não se trata de menosprezar o poder do conhecimento sobre o risco, que é importante nas técnicas e nos conjuntos das práticas de prevenção e promoção em saúde, mas de sinalizar possíveis questões problemáticas em seu uso popularizado. Diante das repercussões e dos desdobramentos que a noção de risco tomou, pouco se tem falado sobre relatividade do risco, o que inclui, na centralidade dessa discussão, alguns aspectos históricos, culturais, políticos, morais e tantos outros presentes na nossa sociedade, que é tão plural. Por isso acreditamos na abordagem da saúde na ótica dos direitos humanos, especialmente aquela vinculada à redução de danos, que parece ser uma boa aposta nas ações e estratégias de cuidado na lógica territorial.

\section{O Dialeto de Guerra}

Já que destacamos a redução de danos, uma estratégia de trabalho por meio de ações comunitárias em saúde, precisamos falar também sobre a linguagem comumente adotada no início das prevenções de HIV/aids. No Brasil, a redução de danos foi adotada como uma tecnologia de saúde pela primeira vez no estado de São Paulo, em Santos, em meados de 1989, quando elevados índices de transmissão do HIV tinham relação com o uso frequente de substâncias psicoativas do tipo injetável (Elias \& Bastos, 2011). No entanto, a implantação dessas estratégias tem enfrentado diversos gargalos na rede de saúde. A exemplo disso, as políticas de saúde parecem travar uma verdadeira cena de "guerra às drogas" na defesa pelo proibicionismo e pela abstinência total dos consumidores dessas substâncias, uma lógica inversa ao que pretende a redução de danos. Trazendo para o contexto da pandemia do novo coronavírus, a situação parece ter ganhado outros "heróis" - profissionais de saúde - que atuam fortemente na chamada "linha de frente" da guerra, além dos combatentes e recuperados, que juntos enredam uma disputa global em meio às crises. Enfim, esse campo bélico 
de lutas, enfrentamentos, combates e medição de forças foi visto nas experiências contrárias à redução de danos durante as várias epidemias de aids e, agora, fortalece-se também na arena da covid-19.

Sontag (2007) relembra que o uso de metáforas militares para se referir a doenças ocorreu com a tuberculose, com o câncer e, posteriormente, com a aids. São palavras como "inimigo", "mal", "luta", "combate" e outras que acabam sendo transferidas de um contexto bélico e fazendo parte do imaginário coletivo. Para a aids, ainda no início da epidemia, diante dos poucos conhecimentos sobre a doença, instaurou-se uma espécie de pânico moral na sociedade, e, com isso, um repertório bélico começou a se tornar comum tanto no meio informal como nas ações governamentais. O uso dessas metáforas militares, mesmo que não pareça, corrobora significativamente para a estigmatização dessas doenças e, por extensão, daqueles sujeitos que estão adoecidos.

Enquanto o dialeto de guerra parece se articular com uma proposta de remissão de sintomas e com a própria cura, a proposta de reduzir danos tem como direção a ética do cuidado em saúde. Cecílio e Merhy (2003), por exemplo, destacam a importância da apropriação do cuidado coordenado por meio da criação de pontos e pontes de contato entre as lógicas da rede de saúde, fortalecendo a relação usuário-profissional e fomentando as práticas horizontalizadas e em equipes. Por isso, chamamos atenção para a forma como estamos dialogando (e ao mesmo tempo colocando em prática) as estratégias da linguística aplicadas nos discursos da pandemia.

Sob um olhar certeauniano, as estratégias correspondem a um cálculo de relação de forças mobilizado por um sujeito detentor de algum tipo de poder que, por esta via, "[...] postula um lugar capaz de ser circunscrito como um próprio e, portanto, capaz de servir de base a uma gestão de suas relações com uma exterioridade distinta" (Certeau, 1994, p. 46). As estratégias são cálculos operacionais, ou, ainda, mecanismos ideológicos de manipulação, que os sujeitos de poder e saber (Estado, empresa, exército etc.) utilizam para produzir, e reproduzir, os espaços particulares de exercício de poder. Aqui, as estratégias - por meio das práticas cotidianas - acabam por reforçar os instrumentos coercitivos e reguladores do poder (Albuquerque, 2009).

Assim como no início da epidemia de aids na década de 1980, agora, na pandemia do novo coronavírus, o novo fez com que a sociedade ficasse detida sob influências de personalidades científicas, mídia, religião e política. Isso nos submete a discursos controversos, moralidades e polarização das relações sociais, que potencializam o discurso bélico, repercutem nas ações e impactam nas políticas de saúde.

\section{Vulnerabilidades}

A ideia de vulnerabilidade, tema comum à discussão de saúde pública, surgiu em estudos no Brasil com a terceira e mais explosiva epidemia de HIV. Ayres, Calazans, Saletti Filho e França Junior (2006) trouxeram essa discussão aplicada a um conjunto de aspectos de cada sujeito e da sua coletividade que se relacionam ao grau e à forma de exposição a uma dada situação e, de modo indissociável, ao maior ou menor acesso a recursos adequados para proteção e amparo em situações tidas como indesejáveis. Por isso, a vulnerabilidade pode ser instituída em três blocos ou dimensões: individual, social e programática. Ou seja, 
a vulnerabilidade é um processo dinâmico e crítico, que se atualiza nas relações de vida permanentemente e que inclui aspectos de cada sujeito, da sociedade na qual este está imerso e das instituições de apoio. A aplicação desse conceito nos faz entender que as diferentes iniquidades em saúde influenciam no processo de adoecimento e cuidado, em face do HIV, e que se estabelecem no campo da redistribuição dos serviços. Aqui podemos colocar as questões de gênero, raça e classe como condicionantes de um processo de determinação social em saúde. São marcadores sociais que se interseccionam e engendram discriminações, violências, negações e embarreiramentos de forma individual, social e institucional. Essas consubstancialidades ampliam a forma de conceber a aids e, agora, a covid-19.

Werneck e Carvalho (2020) mostram que, quando o novo coronavírus chegou ao Brasil, logo encontrou um alto número de populações vulneráveis. O índice elevado de desempregados, pessoas vivendo em condições precárias de habitação e saneamento, sem acesso à água e em situação de aglomeração, formam elementos que tornaram ainda mais difícil a contenção do vírus. Pessoas em situação de rua, pessoas indígenas, pessoas LGBT, crianças e adolescentes, moradores de periferias, todos enfrentam um outro cenário de sobrevivência e proteção em meio à pandemia. Exemplo disso é o primeiro caso de covid-19 registrado no estado do Rio de Janeiro, onde Cleonice, uma empregada doméstica, residente em região periférica, foi infectada pela "patroa" - que havia retornado recentemente de uma viagem para a Itália - e faleceu dias depois (Simões, 2020). A aids já havia nos chamado atenção para o quão as vulnerabilidades se interseccionam e como produzem formas, ao mesmo tempo, tão individuais, mas também tão coletivas no processo de determinação em saúde.

\section{Prevenção}

É comum profissionais de saúde informarem aos usuários dos serviços sobre os diferentes métodos de prevenção, incluindo a representação gráfica de uma típica mandala que aponta as diferentes formas de prevenção da aids. Para além de outras estratégias de cuidado, a principal delas é o uso do preservativo (Gutierrez et al., 2019). Os preservativos internos e externos previnem várias infecções sexualmente transmissíveis e são uma das principais formas de reduzir possíveis danos à saúde, aliados às informações educativas. Na pandemia do novo coronavírus, os principais instrumentos de prevenção são o isolamento físico e a higienização das mãos. Além disso, o uso de máscaras tem sido uma regulamentação da maioria dos governos municipais e estaduais no Brasil (Oliveira, Lucas, \& Iquiapaza, 2020), mesmo cientes de que a máscara não é a principal forma de prevenção para a covid-19 e que ainda não há muitas evidências sobre a eficácia de uso comunitário, diferentemente do preservativo para a prevenção do HIV. Ambos, máscara e preservativo, cobrem regiões do corpo, embarreiram a passagem de um vírus e devem estar aliados a outras estratégias de educação em saúde. Claro que essa metáfora imprime um conjunto de outras questões que não estão apontadas aqui. Todavia, destacamos que as políticas e campanhas de prevenções que têm se atrelado à mídia, quase que em um só tom, têm tentado nos convencer a usar tanto a máscara para a covid-19 como o preservativo para a aids. É comum que esses meios transmitam mensagens do tipo imperativo negativo ("não transe sem camisinha"; "não esqueça sua máscara ao sair de casa"). É corriqueiro também que as pessoas que não as utilizam sejam julgadas ou tachadas por não pensarem no coletivo ou oferecerem risco 
iminente ao outro. Essas tentativas de aproximações têm nos mostrado que as estratégias de prevenção não somam apenas um aparelho estrutural de mudanças de hábitos, mas toda uma rede subjetiva que se intercambia no processo de saúde-adoecimento-cuidado da aids e da covid-19.

Além dos mecanismos de barreiras presentes no contexto da prevenção da covid-19 e da aids, observam-se estratégias comportamentais de prevenção. Em meados de 1980, adotou-se a estratégia nos Estados Unidos denominada de Serosorting, que, quando traduzida para o português, pode ser entendida como a escolha do parceiro pelo status sorológico. Essa prática ainda persiste nos dias atuais (Terto Jr., 2015) e consiste na escolha de parceiros sexuais que tenham o mesmo resultado da sorologia para o HIV, com o propósito de manter relações sexuais mais seguras. Já no caso da pandemia da covid-19, notou-se, por exemplo, a estratégia de "circuito fechado", com foco nas crianças. Essa modalidade se caracteriza no fato de crianças serem rodeadas pelos familiares mais próximos e, na maioria dos casos, terem restrições de tocar, abraçar ou beijar todos a sua volta. Assim, famílias com crianças que adotam essa estratégia podem encontrar outras famílias que também cumpram à risca as prerrogativas sanitárias (laconelli, 2020). Essa ideia surgiu baseada na psicanálise, em que a imagem do circuito fechado possibilita pensar no funcionamento de seu corpo pulsional e em como se monta na relação com os objetos (Silva, 2016).

\section{Políticas}

A elaboração de políticas voltadas ao HIV culminou na consolidação de diversas leis, programas e coordenações de saúde, assim como teve um papel preponderante na organização dos serviços de assistência especializada às pessoas vivendo com HIV no Brasil (Monteiro \& Brigeiro, 2019). Nos últimos anos, diante das ações de austeridade fiscal, descontinuidade de políticas, exclusão de dispositivos de direitos humanos em saúde, crescimento de uma onda neoliberal e de fundamentalismo religioso, tem sido enfraquecido um projeto reformista de anos, a construção de uma resposta governamental à epidemia de HIV/aids no Brasil (Barros, 2018). Em meio à desmantelada cena política reportada diariamente, temos vivido inúmeros outros problemas na oferta de uma saúde integral, universal e equânime. A emergência de uma política de aids que desse resposta aos gaps sociais e de tratamento gratuito no início da epidemia fez com que houvesse também uma mobilização dos movimentos de reforma sanitária, junto às organizações não governamentais e grupos da sociedade civil na consolidação de um projeto de Sistema Único de Saúde (SUS) (Barros, 2018; Paim, 2018). Para a covid-19, talvez precisemos perceber como o sistema de saúde incorporou tecnologias para regionalizar o tratamento da aids, ofertar medicações, capacitar profissionais e incluir uma lógica de trabalho pautada nos direitos humanos, mesmo com tantos entraves (Monteiro \& Brigeiro, 2019).

Reforçando esse debate, o caminho que vinha sendo trilhado por décadas, mesmo que hoje viva diversas outras questões na organização de um projeto ideal de igualdade, respeito e dignidade, pode ofertar pistas que reforcem o SUS como uma conquista popular e que urge por financiamento, gestão, recursos (humanos e materiais) e uma rede solidificada de atenção à saúde (Paim, 2018). Com a covid-19, o SUS foi mais uma vez cobrado para dar respostas imediatas, sendo alocado como uma verdadeira máquina de inteligibilidade e resistência. 
Algumas respostas exitosas no contexto da aids trouxeram a importância da solidariedade, da aliança e do comprometimento como possibilidade de ação política de prevenção e tratamento (Elias \& Bastos, 2011). A covid-19 nos faz repensar alguns pressupostos de uma vida solidária, sustentável e consciente, que inclui uma vulnerabilidade compartilhada e que se reflete em experiências múltiplas e desiguais entre pessoas, comunidades ou cidades inteiras.

As epidemias de aids mostraram também que as ações de prevenção e tratamento devem ser alvo simultâneos de políticas de saúde (Bastos, 2006). Ou seja, há uma ligação fundamental entre prevenção e tratamento no campo das políticas que também pode ser um indicativo para o caso da covid-19. Essas políticas devem ter uma base na mudança de hábitos, além de abordar as diferentes desigualdades sociais, econômicas e regionais do Brasil. Os tomadores de decisão de todos os setores, em todos os níveis, precisam projetar, implementar e avaliar abordagens de prevenção e tratamento para a covid-19. Portanto, as lições de políticas no contexto da aids podem ajudar a perceber a importância de interromper a transmissão exponencial do SARS-CoV-2, reduzir mortes, prevenir futuros surtos e apoiar comunidades mais afetadas (Hargreaves \& Davey, 2020).

\section{Tratamento}

Um outro campo de disputas históricas de respostas à aids é o tratamento. O Brasil assumiu um papel essencial na luta pela redução dos preços dos medicamentos antirretrovirais, no início dos anos 2000, na tentativa de uma licença compulsória de medicamentos, e, mais recentemente, em 2007, pela efetivação de uma licença específica. Contudo, desde os anos de 1990 que os medicamentos antirretrovirais são distribuídos gratuitamente e, especialmente em 1996, foram incorporados a uma política nacional de saúde (Barros, 2018).

Há quase vinte anos, Farmanguinhos, um laboratório da Fundação Oswaldo Cruz (Fiocruz), iniciou a produção do primeiro antirretroviral, a zidovudina, também conhecida como AZT. A partir de então, o instituto fabrica vários fármacos que constituem o mais conhecido "coquetel antiaids". Logo no início da epidemia de aids, a Fiocruz foi convocada a dar respostas e se tornou reconhecida mundialmente pela sua capacidade tecnológica e científica para o contexto à época (Daniel \& Parker, 2018). Hoje a cena se repete, a mesma instituição tem se articulado em diversas arenas da saúde para oferecer tanto assistência pública como pesquisas éticas.

Ocorre também que, em algum momento da corrida científica e tecnológica da covid-19 (Neves \& Ferreira, 2020), os países mais desenvolvidos podem procurar priorizar a vacinação em massa para seu próprio povo, enquanto milhões de pessoas desfavorecidas, preferencialmente de países menos desenvolvidos, podem morrer sem o acesso. Devido às inúmeras desigualdades e barreiras de acesso aos antirretrovirais, muitas pessoas africanas já foram a óbito no início da epidemia de aids, e a mesma tendência pode ocorrer no cenário da covid-19.

\section{Considerações Finais}

Apesar de serem vírus bem distintos, eles põem em contato, simultaneamente, polaridades entre a salubridade e o insalubre, a morte e a vida, puros e impuros, moralidades e subversões, o passado e o presente, nós e eles. A similaridade de um é o desdobramento do 
outro. Este vertiginoso e transitório jogo de linhas que forjam esse tecido - covid-19 e aids possibilita juntar e fazer coexistirem os dois estados opostos de uma pandemia/epidemia e, assim, produzir verdadeiramente uma miscelânea ou hibridização de perspectivas.

Com a chegada da covid-19, amplificou-se ainda mais o que a aids já tinha nos mostrado - as inúmeras desigualdades e iniquidades sociais, econômicas, raciais e de gênero que repercutem diretamente no acesso e assistência dos serviços de saúde. Sem se atentar às rachaduras de um complexo marcado pela estratificação social, as abordagens de localização do vírus nos corpos, como feito com a aids e agora com a covid-19, mostram o quanto as ações em saúde têm sido individualizantes, negligenciando, assim, questões estruturais e históricas do nosso país. Ao atribuir-se uma responsabilidade individual, vários flancos se abrem na construção de um projeto de saúde que deveria ser de garantia do próprio Estado.

Para que possamos aprender com as experiências exitosas já vividas no campo da aids, a testagem, o tratamento, a prevenção e as políticas referentes ao cuidado com a covid-19 precisam levar em consideração as diferentes complexidades de uma dada realidade social e cultural. O imediatismo, a celeridade dos trabalhos e a urgência das ações podem embaçar as lentes que analisam a diversidade de aspectos de um entorno e turvar a decisão de questões elementares no processo de cuidado e valorização de vidas que importam. Bourdieu (2001) já havia nos alertado que, à medida que a história avança, há uma espécie de "amnésia de gênese", em que não conseguimos lembrar onde tudo começou. Nessa conjuntura, é importante que os fatos fiquem alinhados na história e postulados em uma cadeia de tempo.

Portanto, a covid-19 nos desafia, principalmente, na organização de esforços coletivos e comprometidos com a justiça social e com os direitos humanos, e suas respostas, como visto na epidemia da aids, precisam estar alinhadas com a própria democracia. Com a aids, várias estratégias vieram acopladas à emergência de forças conservadoras, as quais parecem reemergir na covid-19 e, por extensão, trazer consigo estigmas, preconceitos, discriminações, medos e violências, ou seja, colocando em risco a própria vida. Essas pautas precisam atravessar o trabalho de pesquisadores, profissionais de saúde, agentes da mídia, gestores, movimentos sociais, educadores e tantos outros que podem ajudar de forma ética e social esse contexto de crise global.

\section{Agradecimentos}

À Coordenação de Aperfeiçoamento de Pessoal de Nível Superior (Capes) e à Fundação de Amparo à Pesquisa do Estado do Amazonas (Fapeam).

\section{Referências}

Albuquerque, J. L. C. (2009). A dinâmica das fronteiras: Deslocamento e circulação dos "brasiguaios" entre os limites nacionais. Horizontes Antropológicos, 15(31), 137-166. doi:https://dx.doi.org/10.1590/S0104-71832009000100006

Allport, G. (1954). The Nature of the Prejudice. Boston: Beacon Press.

Ayres, J. R. D. C. M., Calazans, G. J., Saletti Filho, H. C., \& França Jr., I. (2006). Risco, vulnerabilidade e práticas de prevenção e promoção da saúde. In G. W. S. Campos, M. C. S. Minayo, M. Akerman, M. Drumond Jr., \& Y. M. Carvalho (Orgs.), Tratado de Saúde Coletiva (pp. 375-417). São Paulo: Editora Fiocruz. 
Barreto, M. L., Barros, A. J. D., Carvalho, M. S., Codeço, C. T., Hallal, P. R. C., Medronho, R. A., . . . Werneck, G. L. (2020). O que é urgente e necessário para subsidiar as políticas de enfrentamento da pandemia de COVID-19 no Brasil? Revista Brasileira de Epidemiologia, 23, e200032. doi:https://doi.org/10.1590/1980-549720200032

Barros, S. G. (2018). Política Nacional de Aids: Construção da resposta governamental à epidemia HIV/aids no Brasil. Salvador: EDUFBA.

Bastos, F. I. (2006). Aids na terceira década. (Coleção Temas em Saúde). Rio de Janeiro: Editora Fiocruz.

Bourdieu, P. (2001). Meditações pascalianas (S. Miceli, Trad.). Rio de Janeiro: Bertrand.

Bourdieu, P. (2003). A dominação masculina (3a ed.). Rio de Janeiro: Bertrand Brasil.

Brasil. (2020). Ministério da Saúde, Centro de Operações de Emergências em Saúde Pública COE-COVID-19. Plano de contingência nacional para infecção humana pelo novo coronavírus COVID-19. Brasília-DF: Ministério da Saúde. Recuperado de http:// biblioteca.cofen.gov.br/wp-content/uploads/2020/04/Livreto-Plano-de-Contingencia-5Corona2020-210x297-16mar.pdf

Castiel, L. D., Guilam, M. C. F., \& Ferreira, M. S. (2010). Correndo o risco: Uma introdução aos riscos em saúde. Rio de Janeiro: Fiocruz.

Cecílio, L. C. O., \& Merhy, E. E. (2003). A integralidade do cuidado como eixo da gestão hospitalar. Campinas: Unicamp.

Certeau, M. (1994). A invenção do cotidiano: Artes de fazer. Petrópolis: Vozes.

Daniel, H., \& Parker, R. (2018). AIDS: A terceira epidemia-Ensaios e tentativas. Rio de Janeiro: ABIA.

Elias, L. A., \& Bastos, F. I. (2011). Saúde pública, redução de danos e a prevenção das infecções de transmissão sexual e sanguínea: Revisão dos principais conceitos e sua implementação no Brasil. Ciência \& Saúde Coletiva, 16(12), 4721-4730. doi:https://doi.org/10.1590/ S1413-81232011001300021

Ferreira, B. O., \& Bonan, C. (2020). Abrindo os armários do acesso e da qualidade: Uma revisão integrativa sobre assistência à saúde das populações LGBTT. Ciência \& Saúde Coletiva, 25(5), 1765-1778. doi:https://doi.org/10.1590/1413-81232020255.34492019.

Goffman, E. (1980). Estigma: Notas sobre a manipulação da identidade deteriorada. Rio de Janeiro: Zahar Editores.

Gutierrez, E. B., Pinto, V. M., Basso, C. R., Spiassi, A. L., Lopes, M. E. D. B. R., \& Barros, C. R. D. S. (2019). Fatores associados ao uso de preservativo em jovens - Inquérito de base populacional. Revista Brasileira de Epidemiologia, 22, e190034. doi:https://doi. org/10.1590/1980-549720190034

Hargreaves, J., \& Davey, C. (2020). Group for lessons from pandemic HIV prevention for the COVID-19 response. Three lessons for the COVID-19 response from pandemic HIV. Lancet HIV, 7(5), 309-311. doi:https://doi.org/10.1016/S2352-3018(20)30110-7

laconelli, V. (2020, 31 de março). Saúde mental em tempos de caos [Áudio em podcast]. Recuperado de https://open.spotify.com/episode/66BIThabngkRTsfG8yl9yM? si=-4bOw1MGT5CjHzf8Ejh3lw

Monteiro, S., \& Brigeiro, M. (2019). Prevenção do HIV/Aids em municípios da Baixada Fluminense, Rio de Janeiro, Brasil: Hiatos entre a política global atual e as respostas locais. Interface Comunicação, Saúde, Educação, 23, e180410. doi:https://doi.org/10.1590/interface.180410 
Neves, A. L. M. \& Ferreira, B. O. (2020). Narrativas entre ciência e política no ativismo da cloroquina. Psicologia \& Sociedade 32, e020006. doi:https://doi. org/10.1590/1807-0310/2020v32240338

Oliveira, A. C., Lucas, T. C., \& Iquiapaza, R. A. (2020). O que a pandemia da covid-19 tem nos ensinado sobre adoção de medidas de precaução? Texto \& Contexto - Enfermagem, 29, e20200106. doi:https://dx.doi.org/10.1590/1980-265x-tce-2020-0106

Paim, J. S. (2018). Sistema Único de Saúde (SUS) aos 30 anos. Ciência \& Saúde Coletiva, 23(6), 1723-1728. doi:http://dx.doi.org/10.1590/1413-81232018236.09172018

Pimenta, D. (2020). Pandemia é coisa de mulher: Breve ensaio sobre o enfrentamento de uma doença a partir das vozes e silenciamentos femininos dentro das casas, hospitais e na produção acadêmica. Tessituras, 8(1), 9-19.

Pozniak, A., Bekker, L. G., Kamarulzaman, A., Gandhi, M., Horton, R., Das, P., \& Beyrer, C. (2020). A COVID-19 conference at AIDS 2020: Virtual. Lancet (London, England), 395(10237), 1598-1599. doi:https://doi.org/10.1016/S0140-6736(20)31026-6

Segata, J. (2020). Covid-19, biossegurança e antropologia. Horizontes Antropológicos, 26(57), 275-313. doi:https://doi.org/10.1590/s0104-71832020000200010

Silva, M. C. A. C. (2016). O sintoma neurótico na criança: Impasses e saídas do Complexo de Édipo. Anais do IV Colóquio de psicanálise com crianças: Pensando a sexualidade da criança no século XXI (pp. 97-101). São Paulo, SP.

Simões, M. (2020, 19 de março). 1a vítima do coronavírus no Rio era doméstica e foi contaminada no Leblon. Exame. Recuperado de https://exame.com/ brasil/1a-vitima-do-coronavirus-no-rio-era-domestica-e-foi-contaminada-no-leblon/

Sontag, S. (2007). Doença como metáfora/Aids e suas metáforas. São Paulo: Companhia das Letras.

Terto Jr., V. (2002). Homossexualidade e saúde: Desafios para a terceira década de epidemia de HIV/AIDS. Horizontes antropológicos, 8(17), 147-158.

Terto Jr., V. (2015). Diferentes prevenções geram diferentes escolhas? Reflexões para a prevenção de HIV/AIDS em homens que fazem sexo com homens e outras populações vulneráveis. Revista Brasileira de Epidemiologia, 18(1), 156-168. doi:https://dx.doi. org/10.1590/1809-4503201500050012

The Lancet. (2020). COVID-19 in Brazil: "So what?". [Editorial]. Lancet (London, England), 395(10235), 1461. doi:https://doi.org/10.1016/S0140-6736(20)31095-3

Unaids. (2019). Programa Conjunto das Nações Unidas sobre HIV/AIDS. Brasília-DF: Unaids Recuperado de https://unaids.org.br/estatisticas/

Werneck, G. L., \& Carvalho, M. S. (2020). A pandemia de COVID-19 no Brasil: Crônica de uma crise sanitária anunciada. Cadernos de Saúde Pública, 36(5), e00068820. doi:http:// dx.doi.org/10.1590/0102-311X00068820

World Health Organization. (2020). Statement on the second meeting of the International Health Regulations (2005) Emergency Committee regarding the outbreak of novel coronavirus (2019-nCoV). Genebra: WHO. Recuperado de https://www.who.int/newsroom/detail/30-01-2020-statement-on-the-second-meeting-of-the-international-healthregulations-(2005)-emergency-committee-regarding-the-outbreak-of-novel-coronavirus(2019-ncov) 
Zhu, N., Zhang, D., Wang, W., Li, X., Yang, B., Song, J., ... Tan, W. (2020). A novel coronavirus from patients with pneumonia in China, 2019. New England Journal of Medicine, 382, 727-733. doi:http://doi.org/10.1056/NEJMoa2001017

Recebido em: 27/06/2020

Última revisão: 27/08/2020

Aceito em: 16/09/2020

\section{Sobre os autores:}

Breno de Oliveira Ferreira: Doutor em Saúde Coletiva pela Fundação Oswaldo Cruz (Fiocruz). Psicólogo e pedagogo. Professor do curso de Graduação e Pós-Graduação em Psicologia na Universidade Federal do Amazonas (UFAM). E-mail: breno.oli@ hotmail.com. Orcid: http://orcid.org/0000-0002-0979-3911

André Luiz Machado das Neves: Doutor em Saúde Coletiva pelo Instituto de Medicina Social da Universidade do Estado do Rio de Janeiro (IMS-UERJ). Psicólogo. Atua no Programa de Pós-Graduação em Saúde Coletiva da Universidade do Estado do Amazonas (UEA) e no Programa de Pós-Graduação em Psicologia da Universidade Federal do Amazonas (UFAM).E-mail: andre_machadostm@hotmail.com, Orcid: http://orcid.org/0000-0001-7400-7596 
